The International Journal of Engineering and Science (IJES)

|| Volume || 6 || Issue || 5 || Pages || PP 01-06 || 2017 ||

ISSN (e): $2319-1813$ ISSN (p): $2319-1805$

\title{
Integrated Approach to Wetland Protection: A Sure Means for Sustainable Water Supply to Local Communities of Nyando Basin, Kenya
}

\author{
Pamella J.A Were-Kogogo ${ }^{1 *}$ and Anyango Dolphine .C. ${ }^{2}$ \\ ${ }^{1}$ Jaramogi Oginga Odinga University of Science and Technology, School of Biological and Physical Sciences, \\ Kenya \\ ${ }^{2}$ University of Kabianga, School of Science and Technology, Biological Sciences Department, Kenya
}

\begin{abstract}
-
Wetlands have a buffering role particularly the ones at the lake shore, functioning like living filters by removing dissolved and suspended pollutants, thereby contributing to keeping lake waters clean and clear. They also purify water by trapping micro-organisms which cause diseases like diarrhea and dysentery. Wetland plants stabilize soils at the water edges, dampen wave action and slow current speed, hence reduce soil/shoreline erosion. Moreover, they play an important role in flood prevention by acting as hydrologic sponges for storing flood waters temporarily and later releasing it slowly. They are also fish breeding grounds and their destruction interferes with fish spawning. Wetlands also provide socio-economic benefits to rural/local communities in form of water for domestic and irrigation purposes, plant materials as building materials, handcraft making materials and medicines. They form an important contribution to fisheries, game hunting, dry season pasture and communal woodfuel. In the Nyando basin wetlands play a very important role in the livelihoods of local communities, through their ecological, hydrological and socio-economic roles. Despite their importance, these ecosystems are under immense pressure from the rural communities through intense agriculture, as well as from urban and industrial developers. They have been intensively cultivated and overgrazed. Their buffering capacity has hence been compromised through eutrophication, overexploitation of their resources, introduction of exotic species and unsustainable utilization for agricultural activities. This has resulted in their degradation and thus they can no longer perform their ecological and hydrological functions. Degradation of wetland ecosystems in the Nyando basin has resulted in increased soil erosion, more sediments getting into the lake leading to slow eutrophication and reduction in water quality, and reduction in water volumes in rivers, loss of potential for groundwater recharge or discharge, loss of biodiversity, aesthetic value and loss of traditional socio-economic benefits. The result is vulnerability of local communities because once a wetland is destroyed restoration may be very difficult and prohibitively expensive. In any case, restoration to the original socio-economic benefits and environmental values would be unlikely. This has had adverse effects on fish catches along the shores and unavailability of clean drinking water leading to prevalence of water borne diseases. The need for a sustainable intervention thus is imperative. This formed the basis for this project with a goal of contributing to improved water quality and supplies to rural communities and livelihoods through sustainable management of the wetlands. An Integrated Ecosystems Management Approach was a viable methodology to adopt in addressing some of these challenges within the basin. Activities undertaken within the project were focused on the protection, rehabilitation and sustainable use of wetlands. Trainings of local communities were done for their empowerment to take charge of their conservation and development agenda instead of leaving it to external agencies. Integrated approach principles were piloted on degraded areas, resulting in improved water quality and supplies, increased economic activities and rehabilitation of various ecosystems. The replication of this in other areas of the basin can thus provide a more sustainable management of these resources for supply of quality water to rural communities whilst improving their livelihoods.
\end{abstract}

Key words: Ecosystems; livelihoods; water management; wetlands; protection, rehabilitation, and sustainable utilization.

Date of Submission: 14 April 2017

Date of Accepted: 30 April 2017

\section{INTRODUCTION}

Lake Victoria Basin supports a rapidly growing population currently estimated at about 32 million people and is, therefore, one of the most densely populated zones of the eastern Africa region. Lake Victoria Drainage Basin (LVDB) is endowed with a variety of extensive wetland ecosystems. These ecosystems are diverse biotopes of vital environmental and socio-economic importance. They provide several benefits to the local communities 
Integrated Approach to Wetland Protection: A Sure Means for Sustainable Water Supply to Local ..

such as source of water for domestic consumption, fishing, agricultural production and water filtration $[1,2]$. They function like living filters because they remove pollutant nutrients and sediments from surface and ground water and reduce the speed of water flow thereby contributing to keeping lake waters clean and clear. Wetlands also play an important role in purifying water by trapping micro-organisms which cause diseases like diarrhea and dysentery [3]. The root system of wetland plants stabilize soils at the water edges and enhance soil accumulation at the shoreline. By dampening wave action and slowing current speed, wetlands reduce soil and shoreline erosion. Moreover, they play an important role in flood prevention by acting as hydrologic sponges for storing flood waters temporarily and later releasing it slowly. Wetlands are also fish breeding grounds and their destruction interferes with fish spawning [4].

The destruction of riverine wetlands in LVDB has resulted in increased soil erosion and reduction in water volumes in rivers. Their existence has further been threatened by human encroachment through subsistence farming, settlements, burning, brick making and biomass harvesting for livestock. Nutrient laden sediments are the major source of the lake's water quality problems along with waste water discharges from major urban areas around the lakeshore [5, 6]. Rural areas have also taken the blame for sediment loading into Lake Victoria [7] from poor farming practices. The increasing magnitude of sediment pollution in Lake Victoria could be attributed to alteration of wetlands riparian areas through various land use changes and dynamics [5, 6]. It has been reported that about $75 \%$ of the Lake Victoria wetland area has been significantly affected by human activities of which about $13 \%$ is severely degraded. Alteration of the riparian zones around Lake Victoria has rendered the protective nature of these areas ineffective or even detrimental to the health of the lake water [5]. In Kenya, the bulk of Nyando wetland has been threatened with degradation through conversion to rice growing. The wetlands, which have both ecological and hydrological functions, have been intensively cultivated and overgrazed. This has resulted in their degradation and thus they can no longer perform their ecological and hydrological function such as trapping of sediments and biodiversity conservation. Instead, these wetlands are now contributing to sediment flux into the lake. This consequently threatens livelihoods of local communities dependent upon these wetlands for their livelihoods.

Wetland policies are in place in Kenya, but specific institutional arrangements and legal instruments to guide sustainable use of wetlands for agriculture are inadequately developed or lacking. Clearly the coping strategies embedded in various sectoral land use policies such as in forestry, crop production, livestock and wildlife management, and urban development need revitalization or rethinking to be effective against the rampant degradation of wetland ecosystems in Nyando basin. The main freshwater issues in the Nyando basin include water quality and quantity concerns, and low assessment of freshwater potential as well as rampant water borne diseases. The over-dependence of the local community on the wetlands resources, wide-scale human degradation, coupled with the recent lake water receding, has placed the wetlands in a more precarious footing in the area. Most of the water resources are also choked with invasive water weed species, notoriously the water hyacinth. This calls for sustained initiatives that would minimize the escalating degradation of these biodiversity-rich wetlands. Most of the people living this region live below poverty level $(<\mathrm{US} \$ 1.00)$, making them to over-exploit and degrade this fragile ecosystem. Further, the divergent communities, local institutions and stakeholders (governmental or otherwise) that surround the Nyando River Basin have varied perceptions on the symbiotic relationships between wetlands ecosystems and their daily activities [8].

The scenarios on the impacts on the land and water resources formed the basis for this project which targeted the degraded wetlands. Hence the piloting of an integrated approach to managing the wetlands. This project attempted to initiate a strategy that will enhance sustainable management and wise use of the wetlands resources. The project emphasized involvement of local communities in management, in collaboration with all stakeholders and thereby improving the livelihoods of the local poor. It suggested appropriate management interventions that target both poverty alleviation amongst the poor communities and protection of fragile ecosystems in the basin.

\section{Objectives}

The overall objective of this project was to contribute to sustainable water supplies to local communities through wetland protection and conservation whilst enhancing their livelihoods.

\section{Specific objectives}

1. To assess the status of wetland ecosystems in Nyando Basin.

2. To determine uses of wetland resources by local communities within Nyando Basin.

3. To train local communities on the wise use of wetland resources.

4. To promote the application of Integrated Approach to wetland conservation by local communities for sustainable water supplies. 
Integrated Approach to Wetland Protection: A Sure Means for Sustainable Water Supply to Local ..

\section{METHODOLOGY}

The project was conducted in Nyando Basin. Activities focused on protection, rehabilitation, and sustainable utilization of wetland resources through strengthening of local communities' capacity and involvement. The project examined ways by which local communities utilize wetland resources in the Nyando Basin of Kenya. This project was undertaken using a variety of methods, including qualitative and quantitative methods. The qualitative methods included Participatory Rural Appraisal (PRA) approaches as described in [9] were used to collect primary data and included focus group discussions, key informant interviews and direct observations. These techniques were used to gather information from the respondents/local residents on value of wetlands to them as well as their understanding of wetland processes. The participatory approaches were suitable for involvement of the stakeholders in the generation of data sets and in capturing the problems and opportunities on wetland resources management in the study areas with a local perspective. Discussion groups were representative of economic and livelihood activities, gender and age. Direct observations were also used to verify and complement information from participatory approaches. The quantitative data was collected using a structured household questionnaire. The quantitative data was analysed using SPSS.

In order to protect and conserve the existing wetlands, trainings through workshops and seminars were conducted for local communities. This was done in collaboration with other stakeholders like Community Based Organizations, Non Governmental Organization's and line ministries such as Ministry Agriculture and that of Forestry. The trainings focused on application of different methods of land and water conservation practices. Principles of Integrated Approach in the wise use of wetland resources were emphasized.

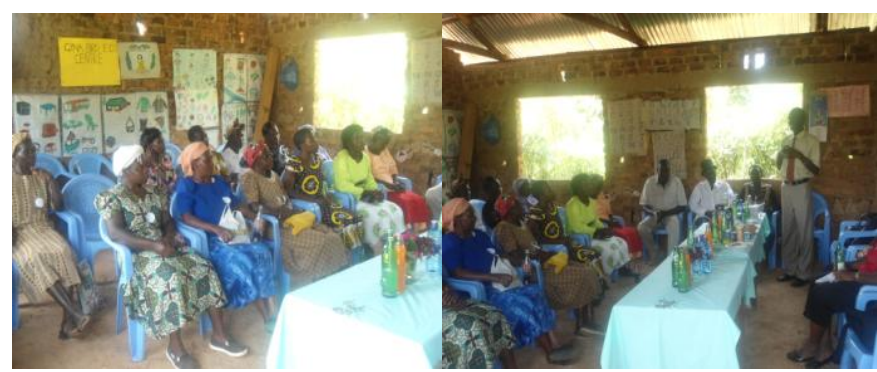

Local communities in a workshop

To protect, conserve and/or rehabilitate degraded wetland ecosystems various activities were promoted. Planting of reeds and papyrus was done at edges of certain water resources to stabilize banks and reduce soil erosion and sedimentation. These were also planted in wetland areas where overharvesting had occurred for the purpose of rehabilitation. Farmers were encouraged to introduce or plant fodder plants on their farms to reduce grazing pressure on wetland vegetation. Agroforestry and afforestation to form woodlots as good agricultural practices were promoted on individual smallholder farms to manage land and hence protection of water resources through reduced soil erosion hence sedimentation/siltation. The use of brick stoves and jiko kisasa for cooking was introduced to rural women farmers inorder to lessen pressure on wetland plants for firewood.

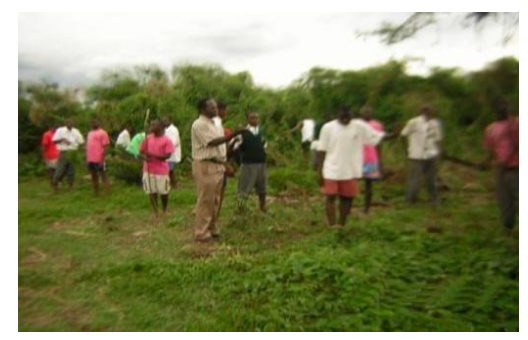

To enhance economic productivity whilst reducing overexploitation of wetland ecosystems different livelihood alternatives and strategies such as bee keeping, goat keeping has been initiated.

Community members planting trees on a degraded wetland

\section{RESULTS AND DISCUSSION}

It became apparent that the major constraints that have encouraged degradation of water resources in the region were low education, poor agricultural technology and knowledge, poverty and lack of alternative livelihoods as well as cultural and social factors. The survey also revealed that there is a strong link between health of these ecosystems and community livelihoods as local people use them for water for agriculture and domestic purposes, fishing, firewood, grazing grounds, construction materials etc. As a result of high human population pressure in the region, these resources become overexploited leading to water scarcity and water of low quality as the ecosystems become degraded. 


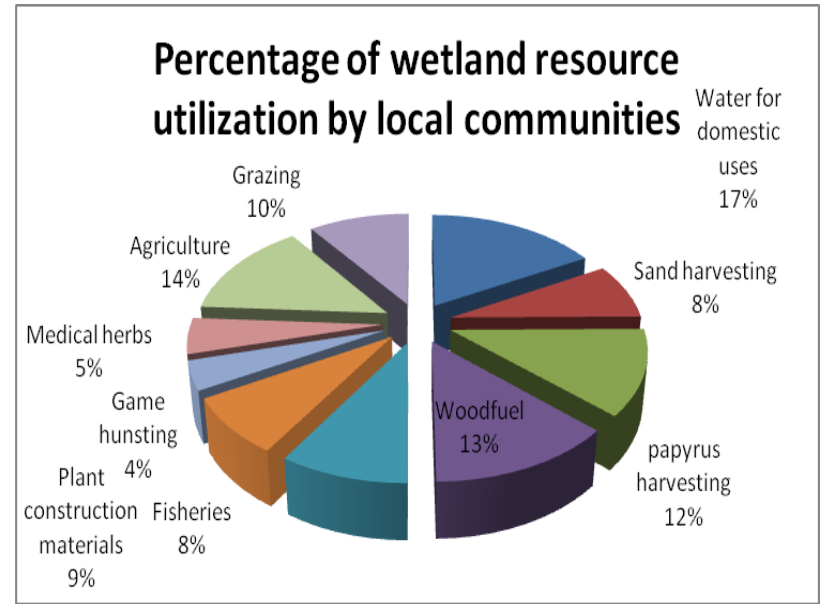

\begin{tabular}{|l|l|l|l|l|l|l|c|l|l|c|}
\hline Activities & $\begin{array}{l}\text { Water for } \\
\text { domestic uses }\end{array}$ & $\begin{array}{l}\text { Sand } \\
\text { harvesting }\end{array}$ & $\begin{array}{l}\text { papyrus } \\
\text { harvesting }\end{array}$ & Woodfuel & $\begin{array}{l}\text { Plant } \\
\text { construction } \\
\text { materials }\end{array}$ & Fisheries & $\begin{array}{l}\text { Game } \\
\text { hunting }\end{array}$ & $\begin{array}{l}\text { Medical } \\
\text { herbs }\end{array}$ & Agriculture & Grazing \\
\hline Frequencies & 83 & 39 & 59 & 64 & 44 & 39 & 20 & 25 & 69 & 49 \\
\hline
\end{tabular}

From this project there is increased awareness and conservation education for schools and school children as has been for the residents.

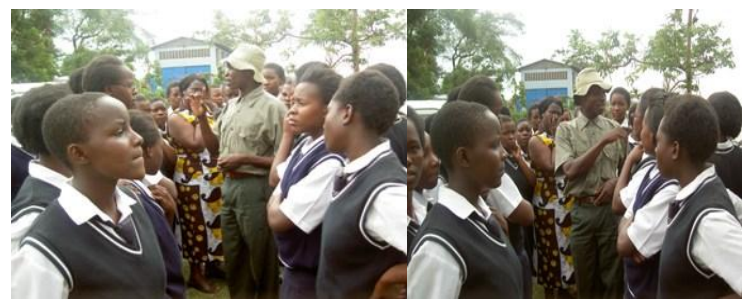

An educative conservation talk to a group of students and their teacher who have come to visit a rehabilitated wetland site. Many schools of this kind visit the site for more information from all over the country. This site is a very important education site as well as recreation site after it rehabilitation.

The widespread practice of various alternative livelihoods has meant improved economic status.

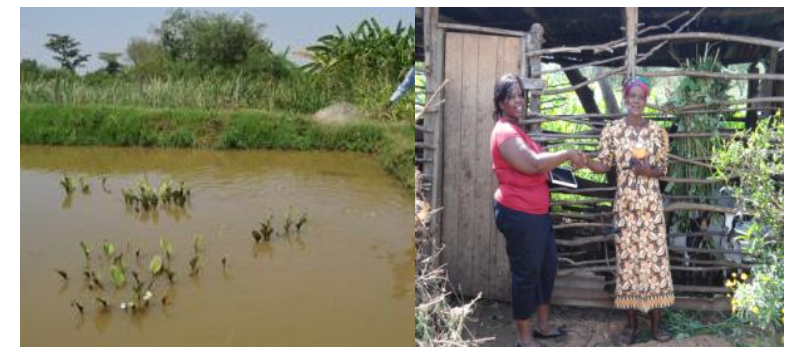

Fish pond

Goat keeping project

Ecotourism as an economic activity is being practiced, offering jobs to local residents.

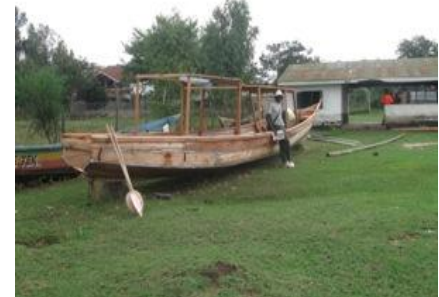

Boat under construction for ecotourism

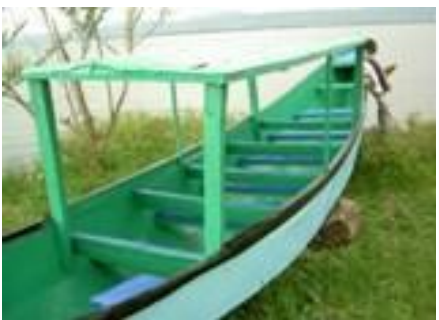

A completed boat for ecotourism 
Integrated Approach to Wetland Protection: A Sure Means for Sustainable Water Supply to Local ..

Reduced pressure on the wetland ecosystems can be seen in sustainable or regular water supply from various springs, water of improved quality and quantity due to low sediment load into the water resources, reduced pressure on wetland plants. There is also increased recharge ability of wetlands as evidenced by sustained presence of water in springs fed by wetlands ecosystems. The aesthetic value of the targeted wetlands has been enhanced.

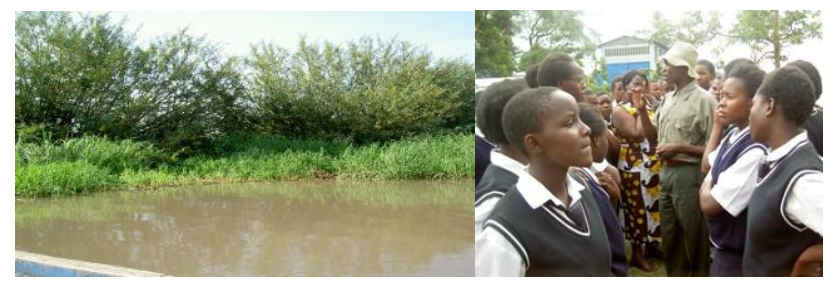

A rehabilitated wetland site

More community participation in conservation is demonstrated in increased woodlots and agroforestry in smallholder farmers' plots or homes, coupled with improved agricultural productivity.

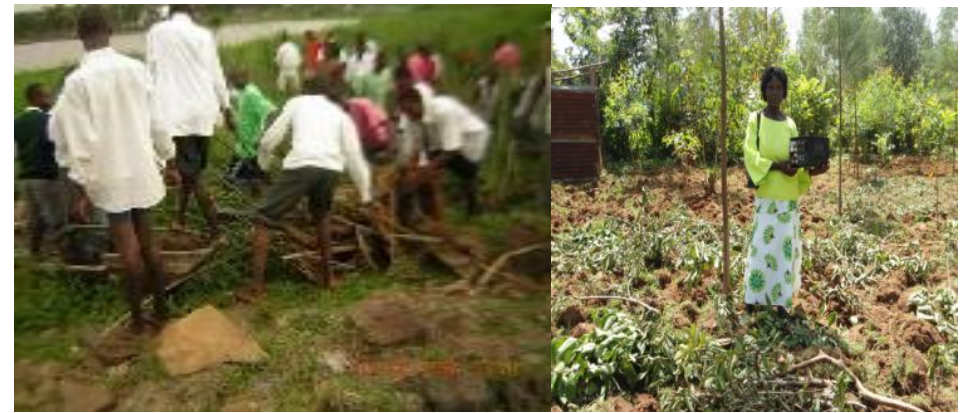

Trees branches cut for firewood

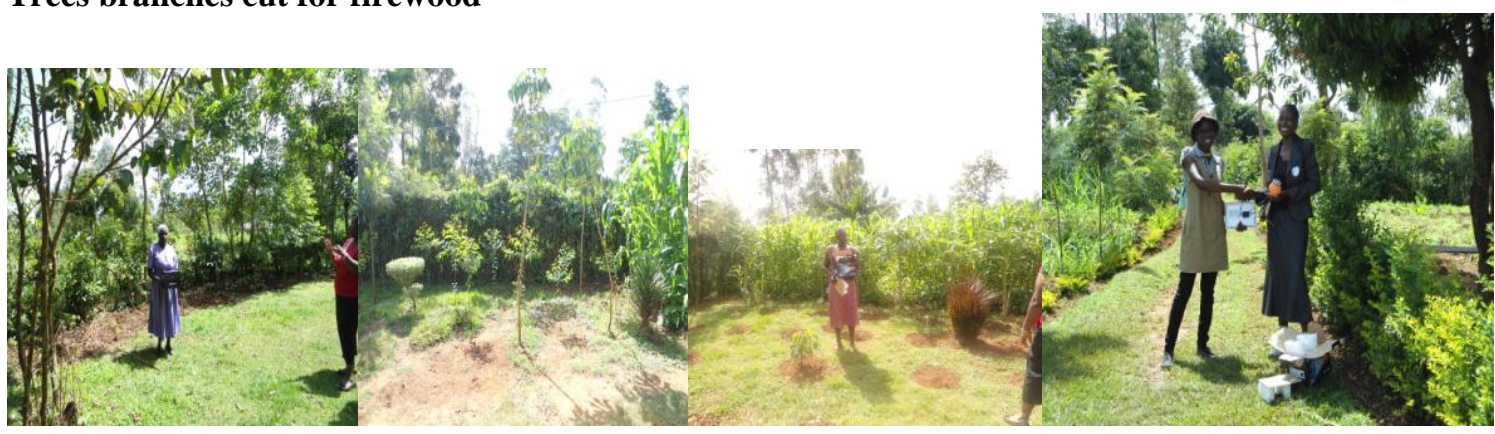

Woodlots

\section{CONCLUSION AND RECOMMENDATIONS}

Environmentally sustainable management of water leads to socio-economic benefits. Considering the environmental function within water management and not as an add-on consideration, does not only provide a platform for addressing ecosystem concerns but also ascertain water of sufficient quality and quantity for use by other sectors. Ecosystem Management Approach as a holistic and landscape scale based approach of managing water quality and quantity is therefore recommended for managing these useful resources. It provides a new perspective for existing management of land and water resources such as farming, forestry, supply of water resources, recreation and tourism, and biodiversity conservation. Incorporating an ecosystem management perspective would help design management activities that are more likely to produce intended results on a sustainable basis. It also has the advantage of incorporating humans into ecosystems as a critical component of ecosystem because people are dependent on ecosystems and are part of ecosystems. The approach can thus lead to sustainability of wetlands and hence sustainable water supplies to communities. Environmentally sustainable management of water leads to socio-economic benefits. The economic returns or improved livelihoods can be an encouragement to ensure support by communities to practice conservation initiatives.

This pilot initiative has generated much interest among the riparian communities and demonstrated successes that need to be replicated and up-scaled in other areas of the LVB while at the same time improving the capacity 
Integrated Approach to Wetland Protection: A Sure Means for Sustainable Water Supply to Local ..

of the communities in the basin wetlands to better manage their ecosystems. This can be made possible through interventions such as improving income generating activities among the wetlands communities of Nyando and other parts of the LVB; rehabilitating new degraded Wetlands sites in the wider LVB; mainstreaming gender awareness in the rehabilitation and conservation of the wetlands.

\section{REFERENCES}

[1]. R.J. Bakema, and L. Iyango, "Engaging Local Users in the Management of Wetland Resources: The Case of the National Wetlands Programme, Uganda," Working Paper No. 3. IUCN Eastern Africa Programme. Forest and Social Perspectives in Conservation, 2000.

[2]. Ramsar Convention on Wetlands, 1999. Guidelines for establishing and strengthening local communities' and indigenous people's participation in the management of wetlands. Resolution VII.8. Resolutions and Recommendations, "People and Wetlands: The Vital Link", 7th Meeting of the Conference of ContractingParties to the Convention on Wetlands (Ramsar,Iran, 1971), San José, Costa Rica, 10-18 May 1999. Ramsar Bureau, Gland, Switzerland.Available at: http://ramsar.org/key_guide_indigenous.htm.

[3]. COWI, 2002. Integrated water quality/limnology study for water quality. Final Report. Part II: Technical Report. Lake Victoria Environmental Management Project.

[4]. Balirwa, J.S., 1998. Lake Victoria wetlands and the ecology of Nile Tilapia, Oreochromis niloticus Linne. A.A.Balkema, Rotterdam, The Netherlands

[5]. D. Kirugara, N. Nevejan, M. Masai, J. Mwamburi, and A. Othina "Identification of pollution sources in the Kenyan part of the Lake Victoria catchment area," Kenya Marine and Fisheries, Kisumu and Laboratory of General Botany and Nature Management, Free University of Brussels, Belgium, 1993.

[6]. J. Ojok, "Assessment of pollution of sediments from selected Lake Victoria bays,". Msc. dissertation, Makerere University, Kampala, Uganda, 2002.

[7]. R.E. Hecky, R. Mugidde, F.W.B. Bugenyi, and X. Wang, 1998, "Phosphorus in Lake

[8]. Victoria waters and sediments: sources, loadings, sinks and anthropogenic mobilization," in Proceedings of the International Conference on Lake Victoria, Jinja, Uganda, 2000.niversity, The Netherlands, 1998.

[9]. Gawler, M., 2000. What are best practices? Lessons in participatory management of inland and coastal wetlands. In: Gawler, M. (ed.) Strategies for wise use of wetlands: Best practices in participatory management.Proceedings of Workshop 1 of the 2 nd International Conference on Wetlands and Development. Wetlands International, Wageningen, The Netherlands.

[10]. Chambers R (1992). Rural appraisal: rapid, relaxed and participatory. Discussion Paper No. 311, Institute of Development Studies, Sussex 